\title{
A Influência do Ambiente Audiovisual na L egendação de Filmes
}

\author{
Antonia Célia Ribeiro Nobre \\ Universidade Estadual do Ceará - UECE
}

Este artigo mostra como a legendação é influenciada por muitos fatores presentes dentro do ambiente audiovisual devido, sobretudo, à função comunicativa audiovisual, à composição semiótica, à mecânica da legendação, e às visões e ao comportamento das pessoas envolvidas na produção audiovisual, na tradução e na distribuição, na crítica e no público.

This article shows how subtitling is influenced by many factors among the audiovisual environment, due primarily to the audiovisuals communicative function and semiotic composition; the mechanics of subtitling; and the views and behavior of people involved with the audiovisuals production, translation and distribution, the critics and the public.

\section{Introdução}

Não obstante a importância da legendação como meio de proporcionar o entendimento de filmes estrangeiros por imensas platéias no mundo inteiro, o trabalho do tradutor legendista é pouco valorizado e costuma ser alvo de severas críticas dos espectadores, da imprensa e até de outros profissionais da área de tradução. As críticas, em geral, referem-se a legendas consideradas erradas, ao uso de expressões pouco naturais na língua de chegada ou à omissão de informações. Mesmo os que conhecem pouco a língua de partida arriscam-se a reclamar que as legendas não retratam fielmente as falas do filme.

Por outro lado, diversos estudiosos da tradução audiovisual no Brasil, como Franco (1991), Mouzat (1995) e Araújo (2000), entre outros, têm se manifestado contra este tipo de críticas, consideradas, na sua maioria, superficiais e injustas. Araújo afirma que, em muitos casos, tais 
críticas decorrem do desconhecimento das peculiaridades do ambiente audiovisual e das limitações impostas aos tradutores e comenta que:

"Infelizmente, a maioria dos trabalhos no Brasil sobre o assunto carecem de reflexões mais aprofundadas sobre a influência do ambiente audiovisual no resultado final das traduções. Muitos deles ainda estão centrados apenas no produto, discutindo as soluções dos tradutores, sem levar em conta as restrições impostas ao legendista e ao tradutor para dublagem" (Araújo, 2000: 247)

O presente artigo, objetivando contribuir para esta discussão, aborda vários aspectos da influência do ambiente audiovisual na legendação de filmes, tomando por base, uma análise de minha experiência como legendista do documentário Lady Day- The Many faces of Billie Holiday, além de pesquisa bibliográfica sobre o assunto.

Este estudo faz parte de minha pesquisa de mestrado, que tem como referencial teórico os Estudos Descritivos da Tradução, na visão de Toury (1995), cujos pressupostos incluem a rejeição das abordagens prescritivas adotadas anteriormente pelos teóricos da Tradução. Estes priorizavam apontar falhas nas traduções analisadas e determinar formas "ideais" de traduzir, que passavam a considerar como as únicas aceitáveis. A abordagem descritiva, pelo contrário, propõe observar e descrever as traduções, levando em conta seu processo, produto e função, no contexto em que elas foram realizadas, para entender como essas traduções funcionam na prática e o que ocasiona os comportamentos tradutórios verificados.

Dessa forma, a explicitação dos diversos fatores que normalmente atuam no ambiente audiovisual, exercendo influência sobre a legendação, afigura-se de fundamental importância como peça auxiliar na análise das traduções em bases mais justas, sob a ótica dos Estudos Descritivos da Tradução.

O ambiente audiovisual, conforme considerado neste trabalho, envolve os sub-ambientes de produção, distribuição e exibição dos audiovisuais, com seus respectivos processos e características técnicas, todos os profissionais que atuam nesses sub-ambientes, e também o público alvo e os críticos da mídia cultural.

Constatamos que este complexo ambiente impõe uma série de limitações que influem no trabalho dos legendistas, como será detalhado a seguir. 


\section{A composição semiótica do audiovisual}

A característica básica dos audiovisuais, que os distingue dos outros meios de comunicação é sua composição semiótica - a forma de apresentação de seus conteúdos através de uma multiplicidade de canais acústicos e visuais. Gottlieb (1998) refere-se a quatro canais a serem considerados pelo tradutor de audiovisuais:

"a) o canal auditivo verbal (diálogos, vozes em segundo plano e algumas vezes as letras das canções);

b) o canal auditivo não-verbal (música, sons naturais, efeitos sonoros);

c) o canal visual verbal (créditos, letreiros, cartazes, notícias de jornal e outros textos escritos que aparecem na tela); e

d) o canal visual não-verbal (imagens, com sua forma de composição e fluxo)" Gottlieb (1998:245).

O entendimento do filme depende da captação pelo espectador das informações contidas em todos esses canais e não apenas nas legendas. Dessa forma, faz-se necessária uma perfeita harmonia entre os canais visuais e auditivos, sob pena de confundir e causar desconforto no espectador. Em vista disso, há um momento adequado para cada legenda aparecer e desaparecer, de forma a preservar o sincronismo entre a fala dos personagens, as imagens e a exposição da legenda. É necessário, portanto, que seja feita uma marcação precisa dos momentos de entrada e saída de cada legenda, cabendo ao legendista definir estes momentos, respeitando o ritmo da fala dos personagens, as pausas e os cortes para mudanças de cena, que compõem a linguagem fílmica. Deve-se levar em conta também a velocidade de leitura dos espectadores, pois se o texto das legendas for muito longo em relação ao seu tempo de exposição, o público não vai conseguir lê-las.

Às vezes, o legendista não recebe a fita de vídeo para a tradução, mas apenas a fita cassete de áudio. Nesse caso o seu trabalho é altamente prejudicado, pois ele fica impedido de levar em conta o conteúdo semiótico do filme para a tradução e marcação.

\section{A função comunicativa do audiovisual e o espaço reservado para as legendas:}


Como instrumentos de comunicação, os audiovisuais podem ser usados para transmitir conceitos, informações, mensagens, formar opinião ou, simplesmente, divertir, mas para atingir seus objetivos comunicativos, eles precisam, antes de tudo, ser bem aceitos e assimilados pelos espectadores e, para tanto, necessitam ser dotados de qualidades que os tornem inteligíveis e satisfatórios para o público alvo.

Nesse contexto, o papel da legenda interlingual é o de permitir que o conteúdo de um audiovisual seja entendido por platéias que não dominam a língua em que ele foi produzido. Porém, isso deve acontecer sem que seja prejudicada a apreciação dos demais aspectos do filme pelo espectador.

A esse respeito, Gottlieb (1998:116) alerta que "ninguém vai ao cinema ou liga a TV para ler legendas", portanto elas não devem causar estranheza ao espectador, nem por sua aparência, nem por seu texto, nada que possa distrair a atenção que o espectador deve devotar ao conteúdo do filme. Sob essa ótica, é importante que as legendas sejam tão discretas que, no decorrer da projeção do audiovisual, dêem a ilusão de que nem estão na tela, embora permaneçam ali bem legíveis. Rodrigues(1998) diz que o espectador deve ter a impressão de estar ouvindo o que realmente está lendo.

Recomenda-se, em vista disso, que as legendas apresentem boa visibilidade, contornos precisos e mantenham-se firmes na tela, sendo exibidas numa velocidade e numa posição que permitam a sua leitura e ainda sobre tempo e espaço para o espectador apreciar as imagens e demais elementos verbais e não verbais do audiovisual. (Luyken et al, 1991; Ivarsson, 1998; Gottlieb, 1998).

Este aspecto acarreta as seguintes restrições de tempo e espaço para a colocação das legendas: a legenda não deve ter mais de duas linhas nem ocupar mais de dois terços da largura da tela. Nos filmes de $35 \mathrm{~mm}$, cada linha deve ter um máximo de 32 a 40 caracteres (dependendo do sistema de projeção e do tipo de software utilizado na legendagem), e nos filmes de $16 \mathrm{~mm}$, até 24 ou até 27 caracteres por linha.

O tempo disponível para exibição de cada legenda é limitado em função da quantidade de texto, da velocidade de leitura dos telespectadores e da necessidade técnica de deixar aproximadamente 1/2 segundo de intervalo entre uma legenda e outra. Cada linha de legenda corresponde a até 2 segundos. Luyken et al (1991: 42-45) 


\section{Redução textual, supressão ou acréscimo de informações}

As restrições de tempo, espaço e número de caracteres permitidos para as legendas, mencionadas no item anterior, tornam necessária a redução do texto dos diálogos do filme na confecção das legendas. Assim, cabe ao legendista encontrar formas de transmitir a mesma mensagem com menos palavras, às vezes sendo necessário suprimir informações. Portanto, ele precisa conhecer o público alvo para saber quais informações podem ser suprimidas sem prejudicar o entendimento do filme, ou até acrescentar informações, quando necessário.

$O$ fato de ser uma tradução de um texto oral para um escrito também resulta em redução textual, pois é comum utilizar-se menos palavras quando se escreve do que quando se fala para transmitir uma mesma mensagem. Gottlieb (1998:247) considera que a redução textual chega a ser benéfica para a elegância do texto e a eficácia da mensagem transmitida na legenda, uma vez que a fala normalmente apresenta muitas repetições desnecessárias e o espectador já dispõe das informações contidas nos outros canais do audiovisual para complementar seu entendimento do filme.

\section{O processo de legendagem/legendação}

O processo de legendagem é outro fator que exerce grande influência no trabalho do legendista. Coforme já descrito por Luyken et al (1991), Gottlieb (1998), Ivarsson (1998) e Araújo (2000), esse processo depende dos equipamentos, técnicas e materiais disponíveis, mas em geral, envolve as seguintes etapas: a comparação do roteiro com a fita matriz ou transcrição das falas, quando necessário; gravação da cópia de trabalho com TCR; marcação; tradução e composição das legendas; inserção das legendas; revisão; aprovação pelo cliente; e, finalmente, transmissão ou gravação das legendas no filme.

Inicialmente, o roteiro disponível, que pode ser de pré-produção ou de pós-produção, é comparado com a fita matriz e corrigido, quando necessário. Caso o roteiro do audiovisual não esteja disponível, o conteúdo textual da fita deve ser transcrito pelo legendista, como aconteceu na legendação do documentário Lady Day - The many faces of Billlie Holiday, que serviu de base para este artigo. A atividade de transcrição mostrou-se muito trabalhosa, exigindo uma audição e entendimento perfeitos das falas dos personagens. Neste caso, o uso de 
termos técnicos específicos do assunto tratado, nomes próprios e jogos de palavras, juntamente com falas apresentando má dicção e traços dialetais dos entrevistados no documentário causaram dificuldades adicionais ao trabalho. Verificou-se que a transcrição de certos trechos pode ficar praticamente inviabilizada se a fita disponibilizada para o legendista não apresentar boa qualidade de audição.

A etapa seguinte do processo de legendação prevê a gravação da cópia de trabalho, sendo o filme copiado em uma fita com TCR (Time Code Reader - indicador de minutos e segundos), para possibilitar a marcação dos momentos de entrada e saída de cada legenda.

Ivarsson (1998:158) alerta que o legendista deve atentar para as pausas e cortes por ocasião da marcação, não só para garantir o sincronismo dos canais acústicos e visuais do filme, mas também no sentido de fazer a distribuição lingüística dentro das legendas de forma a manter o suspense do filme e nunca estragar as surpresas.

Na maioria dos países europeus, a marcação é tarefa do tradutor, que a realiza com a ajuda de um software. No Brasil, porém, os legendistas, normalmente, não têm acesso aos softwares de legendação. Fazem uma marcação preliminar, utilizando o TCR (Time Code Reader) e um microcomputador para digitação do texto das legendas e depois passam sua tradução para um técnico (o marcador) que marca de fato a entrada e a saída de cada legenda. Este aspecto do processo no Brasil pode ocasionar falhas na tradução realizada, quando esse técnico, que em geral desconhece a língua estrangeira, introduz mudanças na marcação do legendista.

No caso estudado da legendação do video Lady Day - The Many Faces of Billie Holiday, o marcador teve uma ação importante, pois corrigiu falhas na marcação do tradutor. Porém, em outros momentos, causou a perda de sincronismo por falhas na segmentação de algumas legendas.

$\mathrm{Na}$ fase da tradução, é realizado um processo simultâneo que Luyken et al (1991) apresentam como 3 atividades distintas, para evidenciar os diferentes aspectos do trabalho do legendista, que abrange: (a) a tradução do texto do audiovisual de uma língua para outra, levando em conta o contexto e demais elementos normalmente considerados em uma tradução literária convencional; (b) a conversão do texto do modo oral para o escrito; e (c) a composição das legendas, levando-se em conta a necessidade da redução textual decorrente das restrições de tempo, espaço na tela e número de caracteres permitidos, a conveniência de 
supressão ou acréscimo de informações, definições quanto ao alinhamento, fonte e local de cada legenda na tela, etc.

Em seguida, a marcação e os textos das legendas são revisados e, se necessário, corrigidos. Nesta etapa o revisor pode introduzir muitas mudanças no texto do tradutor como foi observado na legendação do vídeo Lady day - The many faces of Billie Holiday

As legendas então são levadas para a aprovação do cliente, que, via de regra, estabelece previamente uma política de legendação a ser seguida pelo tradutor sob pena de ter seu trabalho recusado ou modificado.

$\mathrm{O}$ processo de legendagem acima descrito mostra que o tradutor não é o único responsável pelo resultado final das legendas, visto que trabalha em conjunto com outros profissionais.

\section{A influência das visões e comportamentos dos participantes do ambiente audiovisual}

O público alvo detém um enorme potencial de influenciar os procedimentos que ocorrem no ambiente audiovisual, pois a maioria desses procedimentos têm seus objetivos direcionados para atender e satisfazer o espectador. Observamos que os processos e agentes participantes do ambiente audiovisual, via de regra, atuam de forma interdependente, simultânea ou encadeadamente, na busca de dotar o filme das qualidades necessárias ao alcance do objetivo comum de conquistar e garantir a aceitação do público alvo.

$\mathrm{O}$ produtor, o distribuidor e a empresa legendadora influem fortemente na legendação ao imporem regras para a confecção das legendas. Por outro lado, depende deles valorizar mais, ou menos, o trabalho do legendista e proporcionar-lhe condições adequadas de trabalho, equipamentos e softwares para legendagem, determinar os prazos para entrega das legendas, a respectiva remuneração etc.

Normalmente, o distribuidor contrata a empresa legendadora, que por sua vez contrata o legendista. O distribuidor é quem normalmente dá o título do filme e depende dele o fornecimento do roteiro do audiovisual a ser legendado, que pode ser definitivo ou de pré-produção. A existência do roteiro definitivo também depende de cuidados do Diretor de produção, que pode ou não providenciar a sua confecção, acarretando maiores ou menores dificuldades para o trabalho do legendista. 
Outro fator de influência na legendação refere-se às concepções de tradução dos próprios legendistas, dos distribuidores, das empresas legendadoras, da crítica e do público espectador, muitos dos quais ainda conservam a visão de que a tradução é transposição de significados estáveis, independentes do contexto, exigindo-se do legendista uma tradução que seja o mais literal possível.

Enfim, todos esses detalhes, que passam despercebidos do público e da crítica exercem enorme influência no trabalho do legendista e merecem ser considerados por quem se dispuser a avaliar legendas.

\section{REFERÊNCIAS BIBLIOGRÁFICAS}

ARAUJO. V.L.S. Ser ou Não Ser Natural, Eis a Questão dos Clichês de Emoção na Tradução Audiovisual. São Paulo, Faculdade de Filosofia, Letras e Ciências Humanas da USP, 2000. 271p. (Tese, Doutorado em Língua Inglesa e Literatura Inglesa e Norte Americana.)

FRANCO, E.P.C. Everything You Wanted to Know about Film Translation (But Didn't Have the Chance to Ask). Florianópolis, UFSC, 1991. 170p. (Dissertação, Mestrado em Letras)

GOTTLIEB, H. Subtitling: Diagonal Translation. In Perspectives: Studies in Translatology,_Dinamarca, Museum Tusculanum Press, 1994, p. 101-121.

. Subtitling In Routledge Encyclopedia of Translation Studies._Ed. Mona Baker, Londres, Routledge, 1998, p. 244-248.

IVARSSON, J. Subtitling. Simrishamm, Suécia, Transedit HB, 1998, $185 p$.

LUYKEN, G.M. et al. Overcoming language Barriers in Television. Dubbing and Subtitling for the European Audience. Manchester, The European Institute for the Media, 1991, 222p.

MOUZAT, A. M. A Forma e o Sentido da Tradução: A Tradução de Filmes por Legendas. São Paulo, Faculdade de Filosofia, Letras e Ciências Humanas da USP, 1995, 180p. (Tese, Doutorado em Semiótica e Lingüística Geral)

RODRIGUES, R. Por Trás das Imagens: Um Estudo da Legendação no Brasil. São Paulo, Faculdade de Filosofia, Letras e Ciências Humanas da USP, 1998. 103p. (Dissertação, Mestrado )

TOURY, G. Descriptive Translations Studies and Beyound. Amsterdam, John Benjamins, 1995. 311p. 